\title{
Significant association of BDNF rs6265 G>A polymorphism with susceptibility to epilepsy: a meta-analysis
}

This article was published in the following Dove Press journal:

Neuropsychiatric Disease and Treatment

\author{
Yue-Long $\mathrm{Xu}^{\mathrm{l}}, *$ \\ Xiu-Xiu Li ${ }^{1}$,* \\ Su-Jing Zhuang' \\ Shi-Feng Guo' \\ Jian-Ping Xiang' \\ Long Wang ${ }^{2}$ \\ Lan Zhou ${ }^{2}$ \\ Bin $\mathrm{Wu}^{3}$ \\ 'Department of Neurology, Linyi \\ Central Hospital, Linyi 276400, \\ Shandong Province, China; \\ ${ }^{2}$ Department of Neurology, Center \\ for Evidence-Based Medicine and \\ Clinical Research, Taihe Hospital, \\ Hubei University of Medicine, \\ Shiyan 442000, Hubei Province, \\ China; ${ }^{3}$ Department of Stomatology, \\ People's Hospital of District Longhua \\ Shenzhen, Shenzhen 518109, \\ Guangdong Province, China \\ *These authors contributed equally \\ to this work
}

Correspondence: Lan Zhou

Department of Neurology, Center for

Evidence-Based Medicine and Clinical

Research, Taihe Hospital, Hubei

University of Medicine, 32 South Renmin

Road, Shiyan 442000, Hubei Province,

China

Tel $+86719880 \quad 1495$

Fax +867198801218

Email 1902764052@qq.com

Bin Wu

Department of Stomatology, People's Hospital of District Longhua Shenzhen, 38 Jing Long Jianshe Road, Shenzhen 518109, Guangdong Province, China Email penta2004@I63.com
Introduction: Previously published articles have suggested that $B D N F$ rs $6265 \mathrm{G}>$ A polymorphism is a potential risk factor for epilepsy. However, the results were not consistent.

Methods: We conducted a meta-analysis to explore the association between BDNF rs6265 $\mathrm{G}>\mathrm{A}$ polymorphism and epilepsy risk. Four online databases were searched, and related studies were reviewed from their inception up to June 20, 2017. ORs and corresponding 95\% CIs were used to calculate the associations of each genetic model. Overall, 10 case-control publications involving 9,512 subjects were included in this meta-analysis.

Results: Significant associations were found between $B D N F$ rs6265 G $>$ A polymorphism and epilepsy (A vs G: OR=0.88, 95\% $\mathrm{CI}=0.83-0.94, P<0.01, \mathrm{I}^{2}=0 \%$; GA vs GG: $\mathrm{OR}=0.88,95 \%$ $\mathrm{CI}=0.79-0.97, P=0.01, \mathrm{I}^{2}=0 \%$; AA vs GG: $\mathrm{OR}=0.79,95 \% \mathrm{CI}=0.70-0.90, P<0.01, \mathrm{I}^{2}=0 \%$; GA+AA vs GG: $\mathrm{OR}=0.85,95 \% \mathrm{CI}=0.77-0.94, P<0.01, \mathrm{I}^{2}=0 \%$; AA vs $\mathrm{GG}+\mathrm{GA}: \mathrm{OR}=0.85,95 \% \mathrm{CI}=0.76-$ $\left.0.95, P=0.01, \mathrm{I}^{2}=0 \%\right)$. Subgroup analysis also showed similar results in an Asian population.

Conclusion: Our meta-analysis indicated that $B D N F$ rs6265 G>A polymorphism might be involved in epilepsy susceptibility, especially in the Asian population.

Keywords: brain derived neurotrophic factor, epilepsy, seizure, polymorphism, variant, rs6265, case-control

\section{Introduction}

Epilepsy is a complex neurological disease that involves transient disturbances in cerebral function, which is mostly caused by pathologic neuronal discharges and characterized by recurrent and spontaneous seizures. To date, more than 50 million people worldwide have epilepsy. ${ }^{1}$ The prevalence of epilepsy is approximately $0.5 \%-1 \%,{ }^{2}$ with a total annual incidence of 50-70 or 190 cases per 100,000 individuals in industrialized and developing countries. ${ }^{3}$ At least $80 \%$ of epilepsy patients live in a developing country, ${ }^{4,5}$ and only $25 \%$ of patients receive basic treatment. ${ }^{6}$ In 2017 , the International League against Epilepsy (ILAE) published a revised operational classification of seizure types with focal onset, generalized onset, and unknown onset. ${ }^{7}$

Morbidity due to epilepsy is more common in children and the elderly. ${ }^{8,9}$ The brain has been proven to be more "seizure susceptible" in childhood and old age. The immature brain mechanisms and degenerative changes may lead to an increased risk of epileptic seizures. ${ }^{10,11}$ Epilepsy is a serious threat to health and will lead to a significant economic burden for the patients and their families, as well as decreased quality of life. Today, epilepsy is not only a disease but also a serious problem in terms of public health, social stability, and economic development. However, current treatments focus on managing 
symptoms with a lot of antiepileptic drugs because the pathogenesis of epilepsy remains unclear. In addition, the treatment and prognosis for epilepsy are not yet satisfactory.

In the past decade, $B D N F$ has been recognized as one of the important neurotrophic factors that could regulate the morphology of neurons and synapse formation, playing a neuroprotective role in the central nervous system. ${ }^{12}$ Animal model studies with transgenic mice also demonstrated that overexpression of BDNF in the brain can interfere with increased excitability and epilepsy risk. ${ }^{13,14}$

Single-nucleotide polymorphisms (SNPs) are drawing increased attention in current studies, because they are one of the most important genetic mutations and could regulate BDNF expression and metabolism. A large amount of research has proven that $\mathrm{rs} 6265 \mathrm{G}>\mathrm{A}$ (with a nucleotide change from guanine deoxyribonucleotide to adenine deoxyribonucleotide) is the most common polymorphism located in the $B D N F$ gene that causes an amino acid change from valine (Val) to methionine (Met), which may contribute to various central nervous system diseases, such as Alzheimer's disease, ${ }^{15}$ Parkinson's disease,${ }^{16}$ depression, ${ }^{17}$ and bipolar disorder. ${ }^{18}$ In 2003, Kanemoto et al published the first study on the association between $B D N F$ rs6265 $\mathrm{G}>\mathrm{A}$ polymorphism and epilepsy susceptibility and did not find any significant association in a Japanese population. ${ }^{19}$ To date, subsequent studies have been published about the relationship between $B D N F$ rs6265 G>A polymorphism and epilepsy susceptibility, but the results were controversial. We therefore conducted this meta-analysis to more precisely assess the association between $B D N F$ rs $6265 \mathrm{G}>\mathrm{A}$ polymorphism and epilepsy susceptibility.

\section{Methods}

This meta-analysis was conducted under the guidance of the Preferred Reporting Items for Systematic Reviews and Meta-Analyses (PRISMA) statement. ${ }^{20}$ All included data were collected from published studies, and there were no ethical issues.

\section{Search strategy}

Four online databases (PubMed, Embase, CNKI, and Wanfang) were searched for relevant studies with the following search strategy on the association between $B D N F$ rs 6265 $\mathrm{G}>$ A polymorphism and epilepsy risk from their inception up to June 20, 2017. The bibliographies of the collected studies and relevant reviews were retrospectively assessed to identify additional articles. Only studies that were written in English and Chinese were included. The following search terms and strategy were used (for example in PubMed):

\#1 Brain Derived Neurotrophic Factor
\#2 BDNF
\#3 rs6265
\#4 \#1 OR \#2 OR \#3
\#5 polymorphism
\#6 variant
\#7 mutation
\#8 \#5 OR \#6 OR \#7
\#9 epilepsy
\#10 seizures
\#11 \#9 OR \#10
\#12 \#4 AND \#8 AND \#11.

\section{Study selection and exclusion}

All selected studies shared the following inclusion criteria: 1) case-control and cohort studies; 2) studies focused on $B D N F$ rs6265 G>A polymorphism and epilepsy risk; 3) all data were based on human subjects; and 4) selected with adequate genotype information or completed OR and 95\% CIs. The exclusion criteria included: 1) case report or review articles; 2) molecular biology research; 3) articles without enough data or that could not be calculated to corresponding OR and a 95\% CI; and 4) articles with duplicated or overlapping data.

\section{Data extraction}

Two reviewers ( $\mathrm{Xu}$ and $\mathrm{Li}$ ) retrieved, read, and extracted the relevant data from selected studies independently. This information was collected and listed in Table 1: author, study publication year, country or ethnic distribution of the subjects, control design, genotyping method, subtype of epilepsy, the distributed number of genotypes in cases and controls, the group and patient age, and the minor allele frequency in the control group.

\section{Statistical analysis}

The Hardy-Weinberg equilibrium (HWE) in controls of each study was calculated by using a chi-square test first. Pooled ORs with 95\% CIs were calculated to evaluate the strength of the relationship between BDNF rs6265 G>A polymorphism and epilepsy risk. Five genotype models were used, including allele contrast (A vs G), co-dominant (GA vs GG and AA vs GG), dominant (GA+AA vs GG), and recessive (AA vs GG+GA) models. Subgroup analyses were also conducted according to stratified design, such as ethnic distribution, control design, disease type, age distribution, and genotyping method. Cochran's Q statistic was used to 


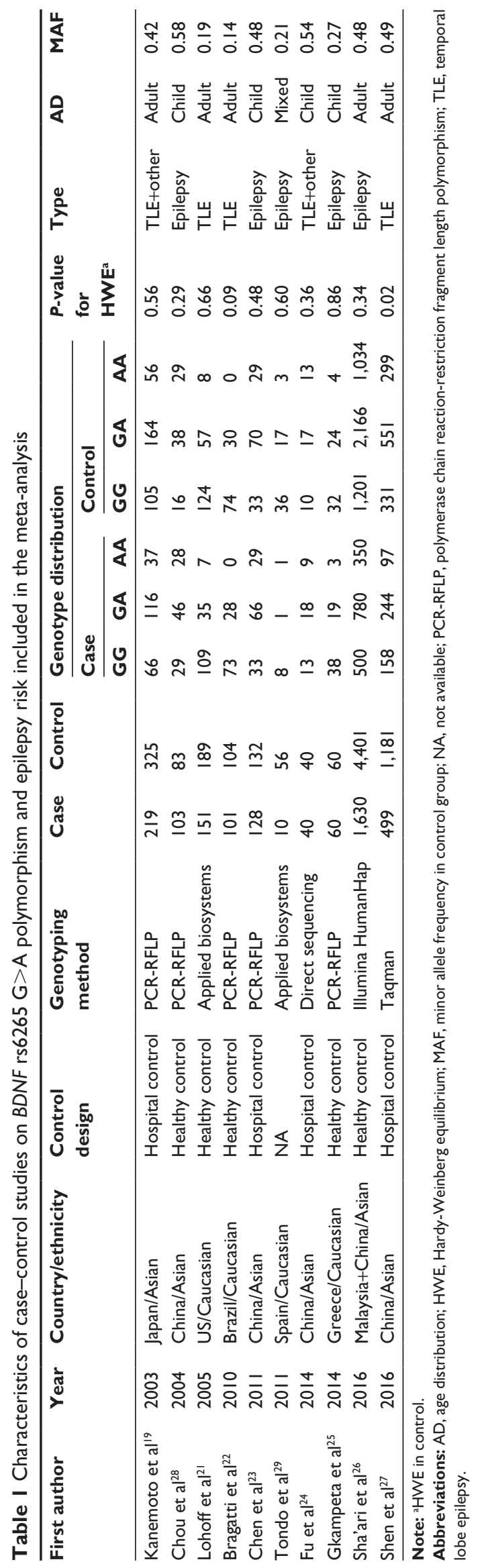

assess the between-study heterogeneity. The fixed-effect model (the Mantel-Haenszel method) was used when the $\mathrm{I}^{2}$ index was less than $40 \%$; otherwise, a random effects model (the DerSimonian and Laird method) was applied. Furthermore, cumulative analyses and sensitivity analyses were conducted to examine the trends and the stability of the results. Publication bias was conducted with Begg's funnel plot and Egger's test. Statistical analyses were performed with STATA version 14.0 (StataCorp LP, College Station, TX, USA). $P<0.05$ was statistically significant.

\section{Results \\ Study characteristics}

In general, 211 studies were identified by a systematic literature search. Figure 1 presents the selection process of the studies. After screening the titles, abstracts, and full articles, 201 articles were excluded. A total of 10 studies involving 2,941 patients and 6,571 controls were included in this metaanalysis. ${ }^{19,21-29}$ Among these studies, five studies focused on adult patients, ${ }^{19,21,22,26,27}$ four studies focused on pediatric patients, ${ }^{23-25,28}$ and one study focused on mixed patients. ${ }^{29}$ Six studies researched Asian populations $s^{9,23,24,26-28}$ and four researched Caucasian populations. ${ }^{21,22,25,29}$ Five studies focused on the subtype of temporal lobe epilepsy. ${ }^{19,21,22,24,27}$ In the genotyping method subgroup, four studies used polymerase chain reaction-restriction fragment length polymorphism, ${ }^{19,22,23,25,28}$ two studies used applied biosystems, ${ }^{21,29}$ one study adopted direct sequencing, ${ }^{24}$ one study used Illumina HumanHap, ${ }^{26}$ and the last study applied the Taqman method. ${ }^{27}$ In terms of the genotype distributions in control groups, only one study deviated from HWE. ${ }^{27}$ All included characteristics of each study are summarized in Table 1.

\section{Meta-analysis}

Meta-analysis was conducted for the combined studies, and the results demonstrated some significant protective effects between rs6265 $\mathrm{G}>\mathrm{A}$ polymorphism and epilepsy susceptibility in all five genotype models (A vs G: $\mathrm{OR}=0.88,95 \% \mathrm{CI}=0.83-0.94, P<0.01, \mathrm{I}^{2}=0 \%$; GA vs GG: $\mathrm{OR}=0.88,95 \% \mathrm{CI}=0.79-0.97, P=0.01, \mathrm{I}^{2}=0 \%$; AA vs $\mathrm{GG}: \mathrm{OR}=0.79,95 \% \mathrm{CI}=0.70-0.90, P<0.01$, $\mathrm{I}^{2}=0 \%$; GA+AA vs GG: $\mathrm{OR}=0.85,95 \% \mathrm{CI}=0.77-0.94$, $P<0.01, \mathrm{I}^{2}=0 \%$, Figure 2 ; AA vs GG+GA: $\mathrm{OR}=0.85,95 \%$ $\mathrm{CI}=0.76-0.95, P=0.01, \mathrm{I}^{2}=0 \%$ ) (Figure $\mathrm{S} 1$ shows other models). Subsequently, analysis excluding the study by Shen et al, which deviated from HWE, also indicated decreased risks in the five genotype models (Table 2). 


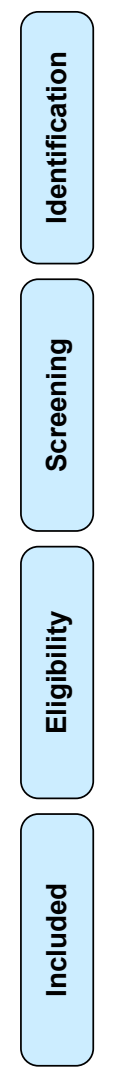

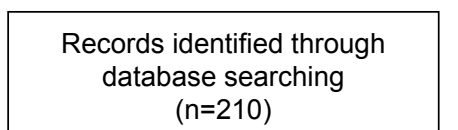
$(n=210)$
Additional records identified

through other sources $(n=1)$

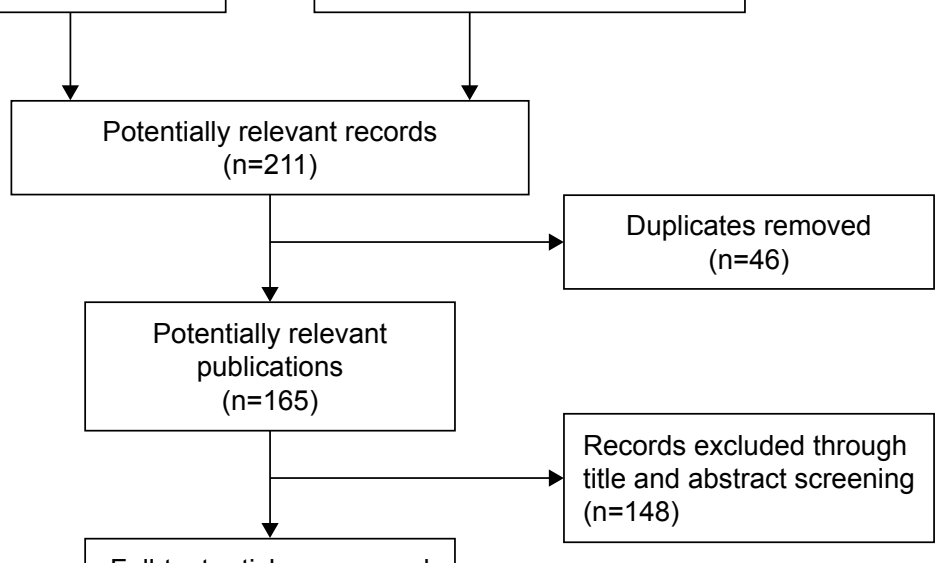

Full-text articles assessed

for eligibility $(n=17)$

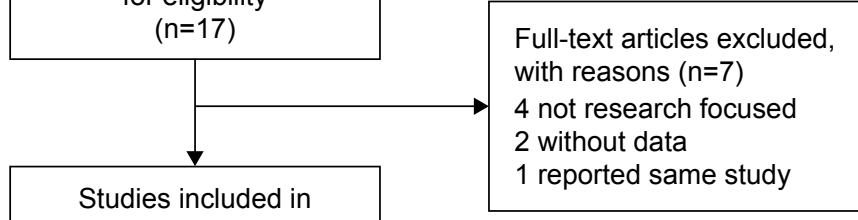

quantitative synthesis

(meta-analysis) $(n=10)$

Figure I Flow diagram of the study selection process.

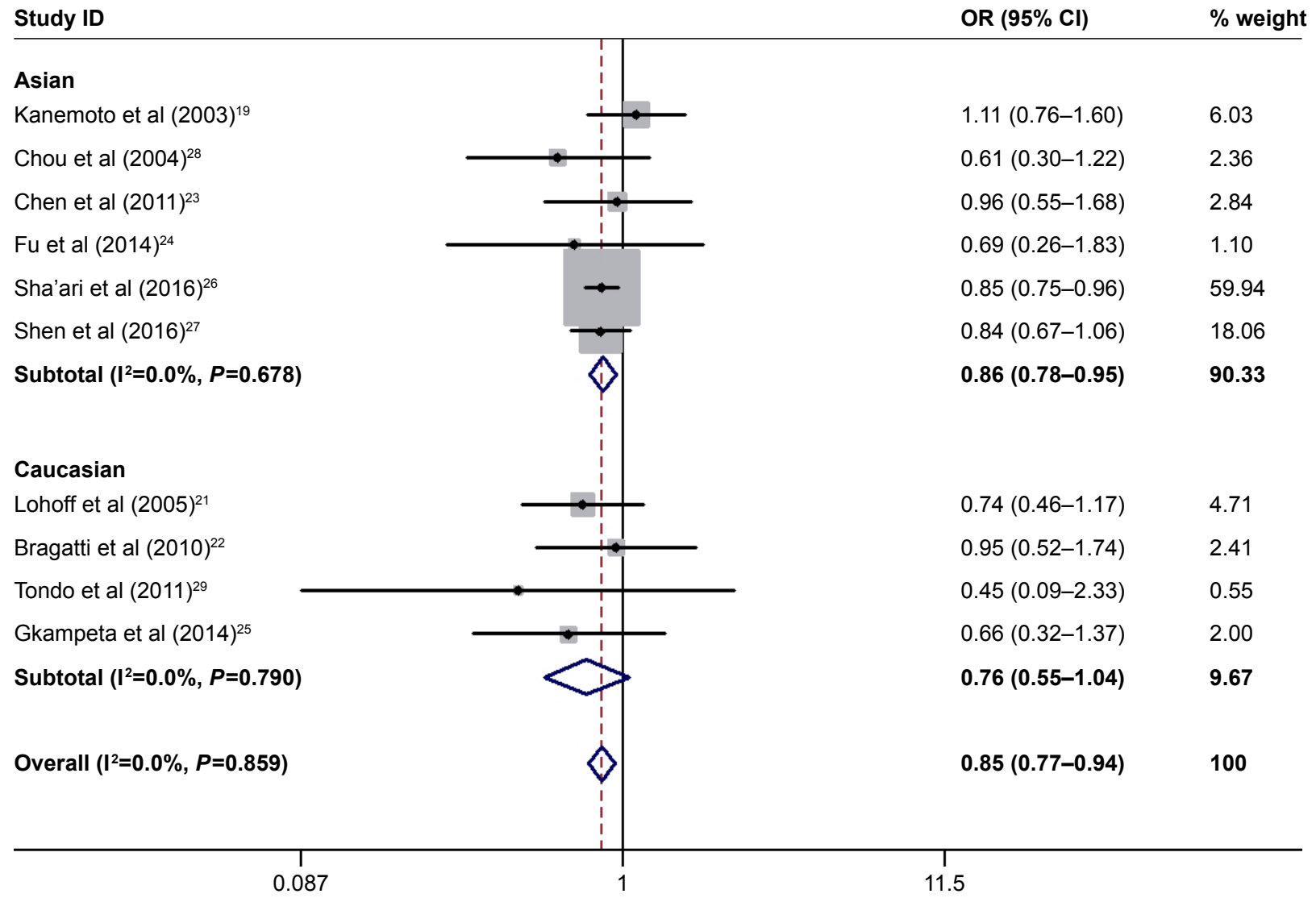

Figure 2 OR and $95 \% \mathrm{Cls}$ of the associations between BDNF rs6265 G>A polymorphism and epilepsy susceptibility in GA+AA vs GG model. 


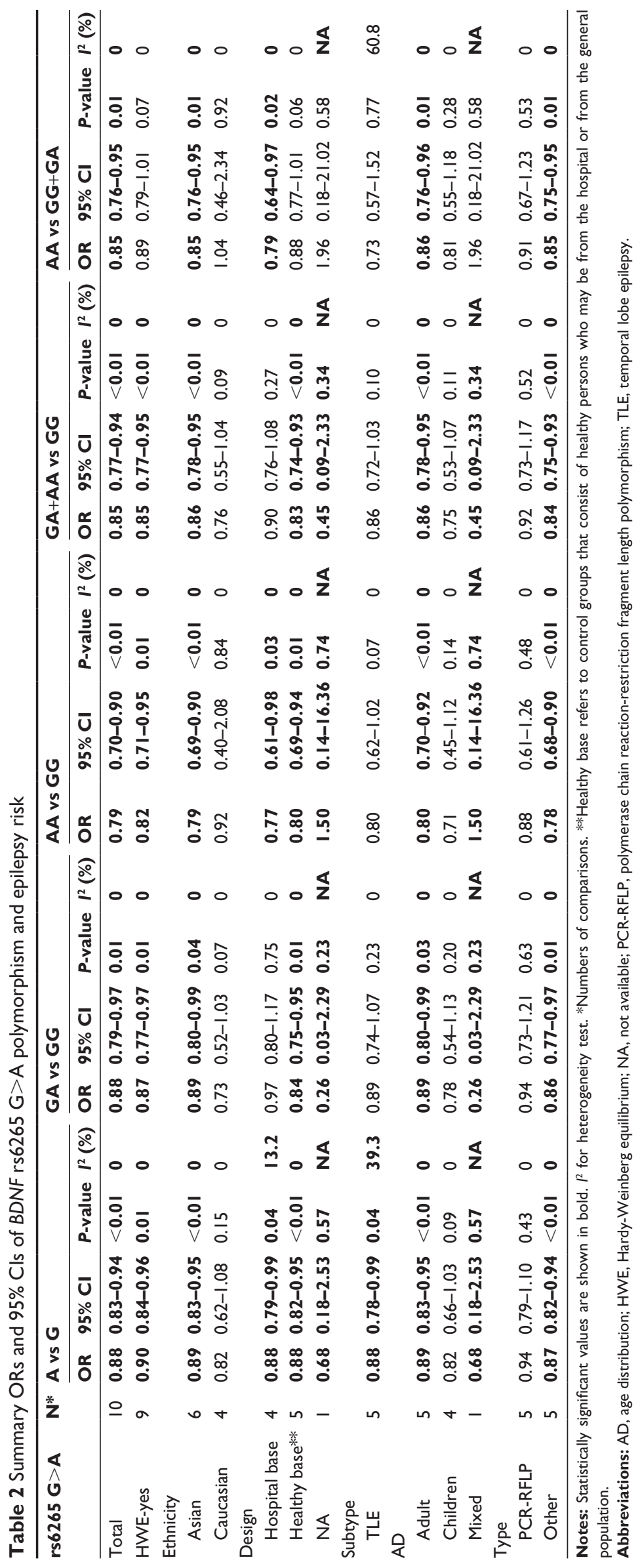


Furthermore, the subgroup analyses were stratified by ethnicity, control design, disease type, age distribution, and genotyping method. All these findings presented consistent effects with the overall analysis results, such as in Asians (A vs G: $\mathrm{OR}=0.89,95 \% \mathrm{CI}=0.83-0.95, P<0.01, \mathrm{I}^{2}=0 \%$; GA vs GG: OR $=0.89,95 \% \mathrm{CI}=0.80-0.99, P=0.04, \mathrm{I}^{2}=0 \%$; AA vs GG: OR $=0.79,95 \% \mathrm{CI}=0.69-0.90, P<0.01, \mathrm{I}^{2}=0 \%$; GA+AA vs GG: $\mathrm{OR}=0.86,95 \% \mathrm{CI}=0.78-0.95, P<0.01, \mathrm{I}^{2}=0 \%$; AA vs $\mathrm{GG}+\mathrm{GA}: \mathrm{OR}=0.85,95 \% \mathrm{CI}=0.76-0.95, P=0.01, \mathrm{I}^{2}=0 \%$ ) and adults (A vs G: $\mathrm{OR}=0.89,95 \% \mathrm{CI}=0.83-0.95, P<0.01, \mathrm{I}^{2}=0 \%$; GA vs GG: $\mathrm{OR}=0.89,95 \% \mathrm{CI}=0.80-0.99, P=0.03, \mathrm{I}^{2}=0 \%$; AA vs $\mathrm{GG}$ : $\mathrm{OR}=0.80,95 \% \mathrm{CI}=0.70-0.92, P<0.01, \mathrm{I}^{2}=0 \%$; $\mathrm{GA}+\mathrm{AA}$ vs $\mathrm{GG}$ : $\mathrm{OR}=0.86,95 \% \mathrm{CI}=0.78-0.95, P<0.01$, $\mathrm{I}^{2}=0 \%$; AA vs GG+GA: OR $=0.86,95 \% \mathrm{CI}=0.76-0.96$, $P=0.01, \mathrm{I}^{2}=0 \%$ ) (Table 2).

Sensitivity analyses were performed by removing each study one-by-one according to the publication date, and the results did not show significant changes (Figure 3 for GA+AA vs GG model and Figure S2 for other models). Cumulative analysis was also performed and presented an apparent protective effect in 2016 from the report by Sha'ari et al (Figure 4 for GA+AA vs GG model and Figure S3 for other models).

Publication bias was evaluated with Begg's tests, and no significant asymmetry was found (Figure 5 for GA+AA vs GG model and Figure S4 for other models). The Egger's test also confirmed these results (A vs G, $P=0.39$; GA vs GG: $P=0.33$; AA vs GG, $P=1.00$; $\mathrm{GA}+\mathrm{AA}$ vs $\mathrm{GG}, P=0.39$; AA vs $\mathrm{GG}+\mathrm{GA}, P=0.99)$.

\section{Discussion}

Epilepsy is one of the most common neurological conditions triggered by the disruption of the abnormal electrochemical activities of the brain's neurological system, thereby resulting in a seizure. Epilepsy affects approximately $0.5 \%$ to $1 \%$ of the general population. Epilepsy can be controlled, but not cured, and more than $30 \%$ of patients have a poor response to medical treatment. ${ }^{30}$

Goldberg and Coulter suggested that the etiology of epilepsy in most patients is still unclear, especially for idiopathic epilepsies, which, without any specific cause, contributed to more than $70 \%$ of seizure symptoms. ${ }^{31}$ However, Scheffer et al postulated that idiopathic epilepsies, nowadays, are known to be of genetic origin, particularly those with early onset - in the first or second decade of life. On the other hand, many symptomatic epilepsies are now classified as structural, metabolic, genetic, post-inflammatory, post-traumatic, or a combination of these etiologies. ${ }^{32} \mathrm{BDNF}$ is one of the crucial nerve growth factors in the family of neurotrophins and plays an important role in the maintenance, regulation, and differentiation of peripheral and central nervous system neurons. ${ }^{33}$ A large amount of research has indicated that abnormal

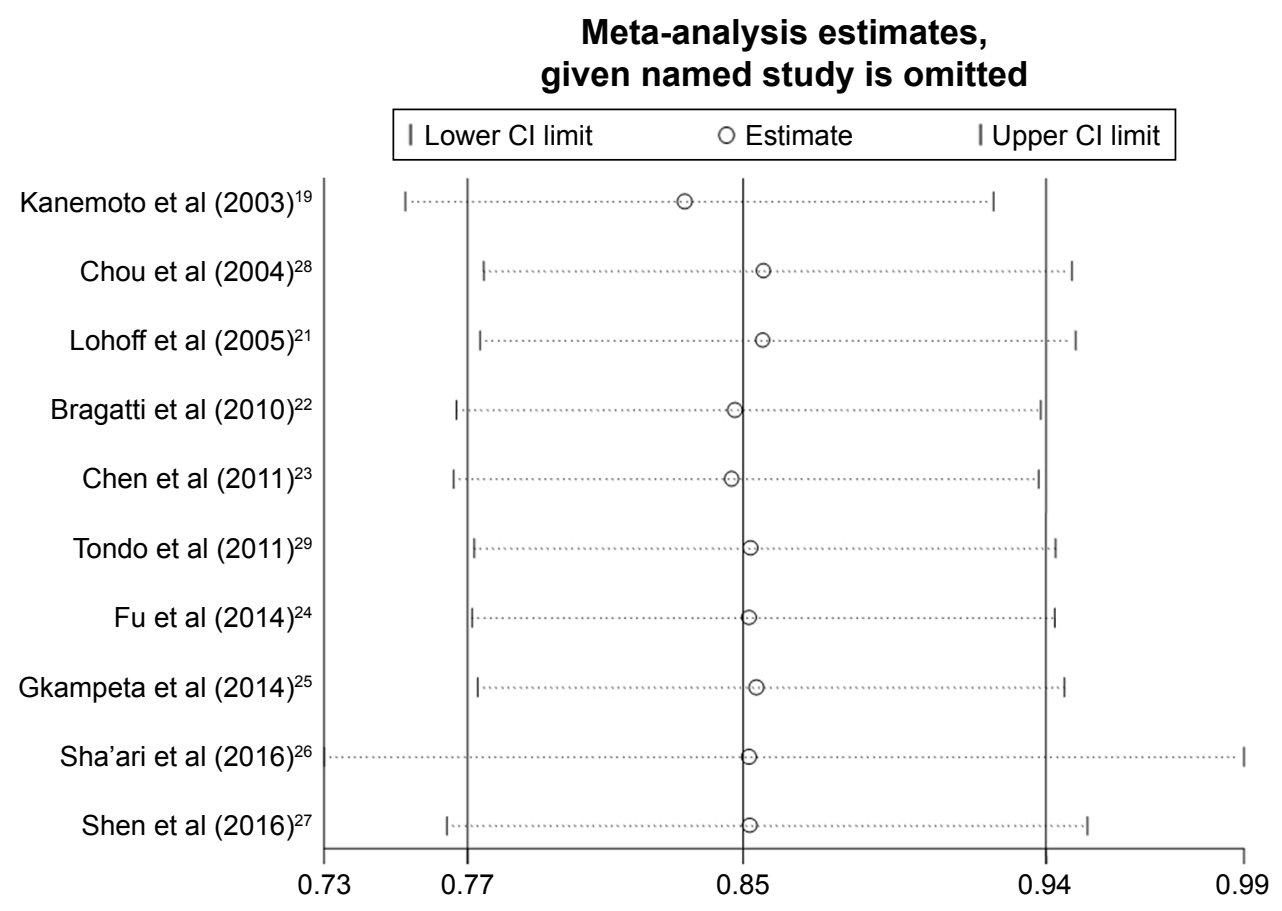

Figure 3 Sensitivity analysis by removing one study at a time to reflect the influence of the individual dataset on the pooled ORs in GA+AA vs GG model of BDNF rs6265 G $>$ A polymorphism. 


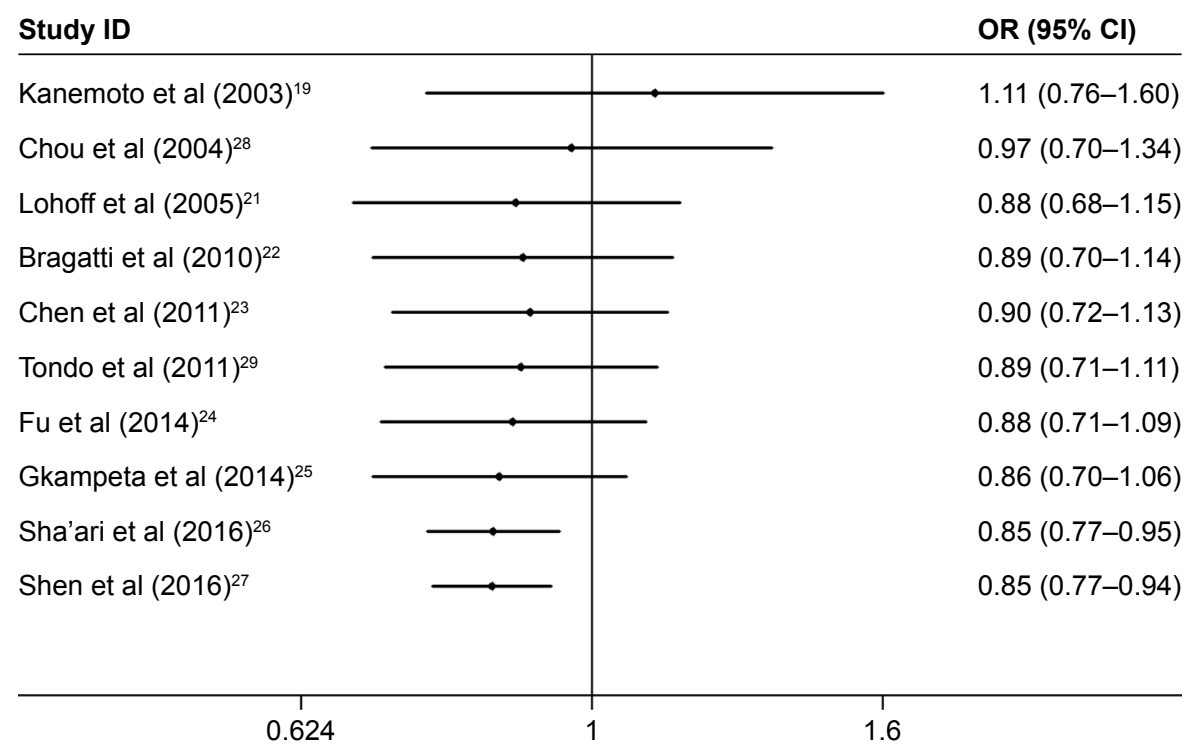

Figure 4 Cumulative meta-analyses according to publication year in GA+AA vs GG model of BDNF rs6265 G>A polymorphism.

expression of BDNF plays a critical role in the pathological process of epilepsy development. Martínez-Levy et al and de Souza Bernardino et al found an increased expression of BDNF transcription in patients with epilepsy, which also supported the idea that the high expression of BDNF in some brain areas may contribute to limbic seizures. ${ }^{34,35}$ Moreover, transgenic mice with high expression of BDNF also indicated an increased seizure risk combined with a hippocampal hyperexcitability. ${ }^{13}$ This cumulative evidence prompted the idea that the abnormalities in the $B D N F$ gene may be responsible for epileptogenesis.

The human $B D N F$ gene is located at the short arm of chromosome $11 \mathrm{p} 13 .{ }^{36}$ Today, several SNP loci of the $B D N F$

\section{Begg's funnel plot with pseudo 95\% confidence limits}

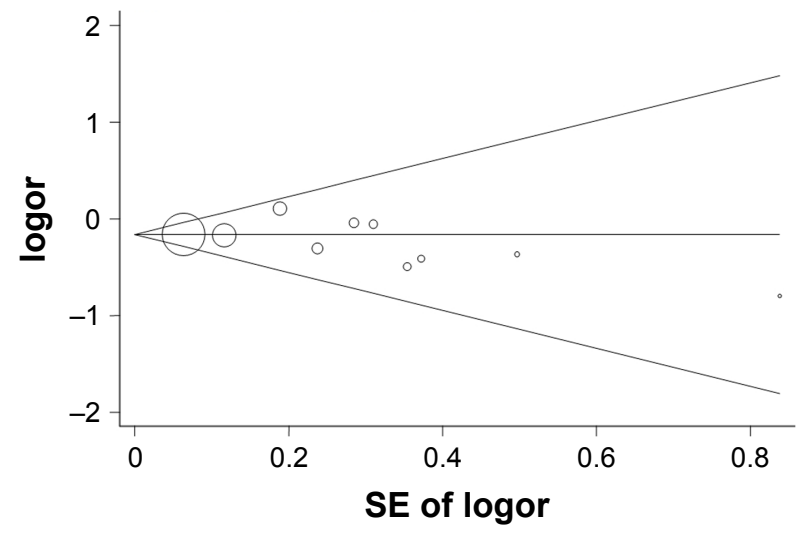

Figure 5 Funnel plot analysis to detect publication bias for GA+AA vs GG model of BDNF rs6265 G>A polymorphism.

Note: Circles represent the number of the studies. gene have been found, and the rs6265 variant is the most common site. This polymorphism substitutes a guanine to adenine $(\mathrm{G}>\mathrm{A})$ change at the nucleotide 196 site and results in a Val to Met substitution at amino acid residue 66 of the pro-BDNF protein..$^{37}$ Bhang et al found that the Met allele of the $B D N F$ val66met polymorphism contributed to a significantly lower serum level of BDNF. ${ }^{38}$ In addition, some studies indicated that the variant-type $B D N F$ ( $B D N F$ Met) would create negative effects to alter the trafficking paths with two important aspects: 1) decreased variant $B D N F$ distributed into neuronal dendrites and targeted to secretary granules, 2) contributed to the impairment of regulated secretion of BDNF. ${ }^{39,40}$ Furthermore, other researchers also found that this change reduces the activity-dependent secretion of BDNF and influences cortical processing, ${ }^{40-42}$ such as low BDNF expression, and protects against seizures with the Met allele of this polymorphism. ${ }^{40,43}$ In 2003, Kanemoto et al conducted the first case-control study to explore the association between the $B D N F \mathrm{rs} 6265 \mathrm{G}>\mathrm{A}$ polymorphism and epilepsy susceptibility in the Japanese population, and the results indicated no statistically significant differences between the epilepsy patients and control groups. ${ }^{19}$ Similarly, Lohoff et al and Bragatti et al did not find any significant association between $B D N F \mathrm{rs} 6265 \mathrm{G}>\mathrm{A}$ polymorphism and epilepsy risk. ${ }^{21,22}$ Since then, a series of studies have been published, but the results were controversial and inconsistent. Sha' ari et al performed a case-control study on an East Asian population and found that the population had a higher risk of developing epilepsy compared with $\mathrm{G}$ carriers in all subjects (dominant model, $\mathrm{OR}=1.18,95 \% \mathrm{CI}=1.04-1.33$ ) ${ }^{26}$ 
Conversely, Shen et al suggested that the A allele might play a protective role against epilepsy risk. ${ }^{27}$

These inconsistent results create confusion. How can we conduct a more precise assessment of the association between $B D N F$ rs6265 $\mathrm{G}>\mathrm{A}$ polymorphism and epilepsy risk? Few studies and small sample size may be the most important factors that contributed to the confusing results. Meta-analysis is a statistical method that combines the results of multiple studies focused on one topic. Therefore, we conducted this meta-analysis with published studies involving a total of 9,512 subjects and found that the A allele mutation of $B D N F$ rs6265 $\mathrm{G}>\mathrm{A}$ polymorphism plays an important protective role against epilepsy development, especially in the Asian population. This result might be due to the greater number of studies conducted in Asian populations with large sample sizes, thereby providing increased statistical efficiency. Moreover, the subgroup analyses based on control design, disease type, age distribution, and genotyping method also indicated some protective effect against epilepsy. Interestingly, the mechanism of $B D N F$ rs6265 G>A polymorphism was more effective in the adult group compared with the pediatric group. It was supposed that the accumulative protective effect of $B D N F$ rs6265 $\mathrm{G}>\mathrm{A}$ mutation would present gradually along with aging.

To the best of our knowledge, this is the first meta-analysis to assess the association between $B D N F$ rs6265 $\mathrm{G}>\mathrm{A}$ polymorphism and epilepsy susceptibility.

\section{Limitations}

Some limitations need to be addressed in the present analysis. First, although we conducted a systematic review and collected eight published studies, the sample size was still small, which could have influenced the results, thereby resulting in some deviations from the truth. Second, only one polymorphism locus ( $B D N F$ rs6265 G>A) was assessed in our analysis. Some influencing factors, such as brain trauma; cigarette smoking, alcohol, and drug use during pregnancy; environmental deterioration; and other gene mutations, could not be comprehensively evaluated. Third, all the included studies were conducted in Caucasian and Asian population. Ethnicity bias may have affected the results and might not be applicable to all people. Despite these flaws, the findings further help us understand the potential associations between $B D N F$ rs6265 G $>$ A polymorphism and epilepsy susceptibility. Furthermore, some positive aspects have been addressed: 1) no heterogeneity exists between the included studies, 2) the results of sensitivity analysis and cumulative analysis are all fairly consistent, and 3) Egger's test and Begg's funnel plots did not present any significant publication bias.

\section{Conclusion}

In summary, this meta-analysis indicated that the $B D N F$ rs6265 G $>$ A polymorphism is associated with epilepsy development, especially in Asian population. More studies with large sample sizes and in-depth research on the mechanism are needed to explore the role of $B D N F$ rs6265 $\mathrm{G}>\mathrm{A}$ polymorphism.

\section{Acknowledgments}

This study was supported by the Foundations of the Science and Technology Department of Hubei Province (no 2016CFB567) and Taihe Hospital (2016BSQD02). These organizations had no role in study design, data collection and analysis, decision to publish, or preparation of the manuscript.

\section{Disclosure}

The authors report no conflicts of interest in this work.

\section{References}

1. Banerjee PN, Filippi D, Allen Hauser W. The descriptive epidemiology of epilepsy-a review. Epilepsy Res. 2009;85(1):31-45.

2. Bell GS, Sander JW. The epidemiology of epilepsy: the size of the problem. Seizure. 2001;10(4):306-314.

3. Sander JW, Shorvon SD. Epidemiology of the epilepsies. J Neurol Neurosurg Psychiatry. 1996;61(5):433-443.

4. Megiddo I, Colson A, Chisholm D, et al. Health and economic benefits of public financing of epilepsy treatment in India: an agent-based simulation model. Epilepsia. 2016;57(3):464-474.

5. Mbuba CK, Ngugi AK, Newton CR, Carter JA. The epilepsy treatment gap in developing countries: a systematic review of the magnitude, causes, and intervention strategies. Epilepsia. 2008;49(9):1491-1503.

6. Tan CT, Avanzini G. Ethical issues related to epilepsy care in the developing world. Epilepsia. 2009;50(5):975-977.

7. Fisher RS, Cross JH, French JA, et al. Operational classification of seizure types by the International League Against Epilepsy: Position Paper of the ILAE Commission for Classification and Terminology. Epilepsia. 2017;58(4):522-530.

8. Global Burden of Disease Study 2013 Collaborators. Global, regional, and national incidence, prevalence, and years lived with disability for 301 acute and chronic diseases and injuries in 188 countries, 1990-2013: a systematic analysis for the Global Burden of Disease Study 2013. Lancet. 2015;386(9995):743-800.

9. Sander JW, Hart YM, Johnson AL, Shorvon SD. National General Practice Study of Epilepsy: newly diagnosed epileptic seizures in a general population. Lancet. 1990;336(8726):1267-1271.

10. Coppola A, Moshe SL. Why is the developing brain more susceptible to status epilepticus? Epilepsia. 2009;50(Suppl 12):25-26.

11. Hernandez-Lain A, Hedley-Whyte ET, Hariri LP, et al. Pathology of bilateral pulvinar degeneration following long duration status epilepticus. Seizure. 2013;22(10):901-904.

12. Stansfield KH, Pilsner JR, Lu Q, Wright RO, Guilarte TR. Dysregulation of BDNF-TrkB signaling in developing hippocampal neurons by $\mathrm{Pb}(2+)$ : implications for an environmental basis of neurodevelopmental disorders. Toxicol Sci. 2012;127(1):277-295. 
13. Croll SD, Suri C, Compton DL, et al. Brain-derived neurotrophic factor transgenic mice exhibit passive avoidance deficits, increased seizure severity and in vitro hyperexcitability in the hippocampus and entorhinal cortex. Neuroscience. 1999;93(4):1491-1506.

14. Govindarajan A, Rao BS, Nair D, et al. Transgenic brain-derived neurotrophic factor expression causes both anxiogenic and antidepressant effects. Proc Natl Acad Sci U S A. 2006;103(35): 13208-13213.

15. Boots EA, Schultz SA, Clark LR, et al. BDNF Val66Met predicts cognitive decline in the Wisconsin Registry for Alzheimer's Prevention. Neurology. 2017;88(22):2098-2106.

16. Altmann V, Schumacher-Schuh AF, Rieck M, et al. Val66Met BDNF polymorphism is associated with Parkinson's disease cognitive impairment. Neurosci Lett. 2016;615:88-91.

17. Cagni FC, Campelo C, Coimbra DG, et al. Association of BDNF Val66MET polymorphism with Parkinson's disease and depression and anxiety symptoms. J Neuropsychiatry Clin Neurosci. 2017;29(2): 142-147.

18. Lee SY, Wang TY, Chen SL, et al. The correlation between plasma brain-derived neurotrophic factor and cognitive function in bipolar disorder is modulated by the BDNF Val66Met polymorphism. Sci Rep. 2016;6:37950.

19. Kanemoto K, Kawasaki J, Tarao Y, et al. Association of partial epilepsy with brain-derived neurotrophic factor (BDNF) gene polymorphisms. Epilepsy Res. 2003;53(3):255-258.

20. Moher D, Liberati A, Tetzlaff J, Altman DG; PRISMA Group. Preferred reporting items for systematic reviews and meta-analyses: the PRISMA statement. J Clin Epidemiol. 2009;62(10):1006-1012.

21. Lohoff FW, Ferraro TN, Dahl JP, et al. Lack of association between variations in the brain-derived neurotrophic factor (BDNF) gene and temporal lobe epilepsy. Epilepsy Res. 2005;66(1-3):59-62.

22. Bragatti JA, Schenkel LC, Torres CM, et al. No major clinical impact of Val66Met BDNF gene polymorphism on temporal lobe epilepsy. Epilepsy Res. 2010;88(2-3):108-111.

23. Chen Y, Wang J, Li F, Qin Y, Huang J. Association of brain-derived neurotrophic factor gene polymorphisms with the risk of pediatric epilepsy. Chin J Behav Med \& Brain Sci. 2011;20(10):907-909. Chinese.

24. Fu L, Luo C, Su B, et al. Study on the correlation between BDNF gene polymorphism and patients with temporal lobe epilepsy. Clin Med Eng. 2014;21(7):835-826. Chinese.

25. Gkampeta A, Fidani L, Clarimon J, et al. Association of brain-derived neurotrophic factor (BDNF) and elongator protein complex 4 (ELP4) polymorphisms with benign epilepsy with centrotemporal spikes in a Greek population. Epilepsy Res. 2014;108(10): 1734-1739.

26. Sha'ari HM, Haerian BS, Baum L, et al. Association of BDNF polymorphisms with the risk of epilepsy: a multicenter study. Mol Neurobiol. 2016;53(5):2869-2877.

27. Shen N, Zhu X, Lin H, et al. Role of BDNF Val66Met functional polymorphism in temporal lobe epilepsy. Int J Neurosci. 2016;126(5): 436-441.
28. Chou IC, Tsai CH, Lee CC, Lin SS, Tsai FJ. Brain-derived neurotrophic factor (BDNF) Val66Met polymorphisms in febrile seizures. Epilepsy Res. 2004;60(1):27-29.

29. Tondo M, Poo P, Naudo M, et al. Predisposition to epilepsy in fragile X syndrome: does the Val66Met polymorphism in the BDNF gene play a role? Epilepsy Behav. 2011;22(3):581-583.

30. Fisher RS, van Emde Boas W, Blume W, et al. Epileptic seizures and epilepsy: definitions proposed by the International League Against Epilepsy (ILAE) and the International Bureau for Epilepsy (IBE). Epilepsia. 2005;46(4):470-472.

31. Goldberg EM, Coulter DA. Mechanisms of epileptogenesis: a convergence on neural circuit dysfunction. Nat Rev Neurosci. 2013;14(5): 337-349.

32. Scheffer IE, Berkovic S, Capovilla G, et al. ILAE classification of the epilepsies: Position paper of the ILAE Commission for Classification and Terminology. Epilepsia. 2017;58(4):512-521.

33. Yogeetha BS, Haupt LM, McKenzie K, et al. BDNF and TNF-alpha polymorphisms in memory. Mol Biol Rep. 2013;40(9):5483-5490.

34. Martinez-Levy GA, Rocha L, Rodriguez-Pineda F, et al. Increased expression of Brain-Derived Neurotrophic Factor transcripts I and VI, cAMP response element binding, and glucocorticoid receptor in the cortex of patients with temporal lobe epilepsy. Mol Neurobiol. Epub 2017 May 19.

35. de Souza Bernardino TC, Teixeira AL, Miranda AS, et al. Wistar audiogenic rats (WAR) exhibit altered levels of cytokines and brainderived neurotrophic factor following audiogenic seizures. Neurosci Lett. 2015;597:154-158.

36. Glatt CE, Lee FS. Common Polymorphisms in the Age of Research Domain Criteria (RDoC): integration and translation. Biol Psychiatry. 2016;79(1):25-31

37. Vulturar R, Chis A, Hambrich M, et al. Allelic distribution of BDNF Val66Met polymorphism in healthy Romanian volunteers. Transl Neurosci. 2016;7(1):31-34.

38. Bhang S, Ahn JH, Choi SW. Brain-derived neurotrophic factor and serotonin transporter gene-linked promoter region genes alter serum levels of brain-derived neurotrophic factor in humans. J Affect Disord. 2011;128(3):299-304.

39. Dincheva I, Glatt CE, Lee FS. Impact of the BDNF Val66Met polymorphism on cognition: implications for behavioral genetics. Neuroscientist. 2012;18(5):439-451.

40. Egan MF, Kojima M, Callicott JH, et al. The BDNF val66met polymorphism affects activity-dependent secretion of BDNF and human memory and hippocampal function. Cell. 2003;112(2):257-269.

41. Wei SY, Chao HT, Tu CH, et al. The BDNF Val66Met polymorphism is associated with the functional connectivity dynamics of pain modulatory systems in primary dysmenorrhea. Sci Rep. 2016;6:23639.

42. Chen ZY, Patel PD, Sant G, et al. Variant brain-derived neurotrophic factor (BDNF) (Met66) alters the intracellular trafficking and activitydependent secretion of wild-type BDNF in neurosecretory cells and cortical neurons. J Neurosci. 2004;24(18):4401-4411.

43. Nectoux J, Bahi-Buisson N, Guellec I, et al. The p.Val66Met polymorphism in the BDNF gene protects against early seizures in Rett syndrome. Neurology. 2008;70(22 Pt 2):2145-2151. 


\section{Supplementary materials}

A

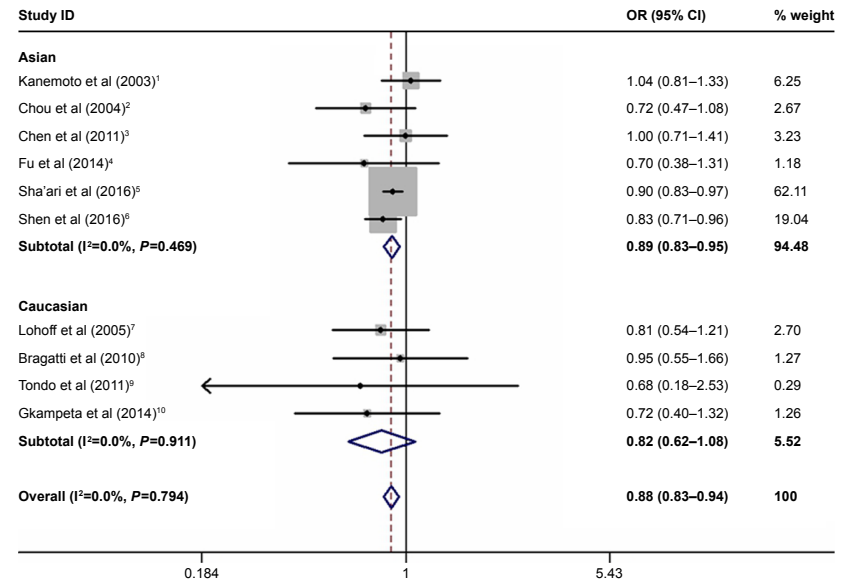

C

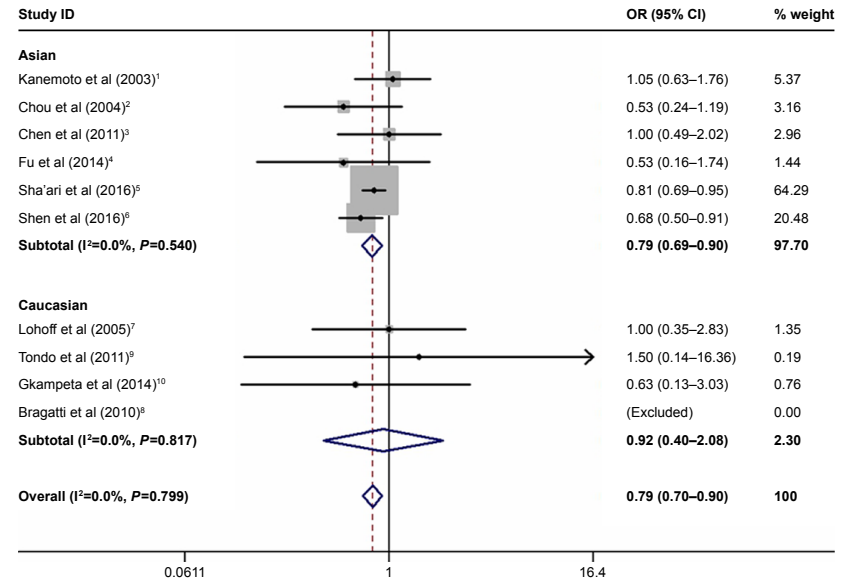

B

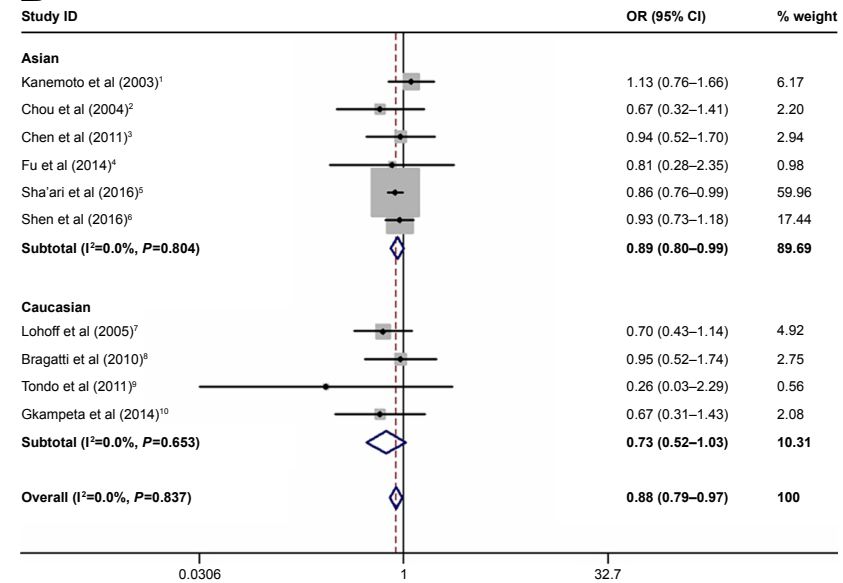

D

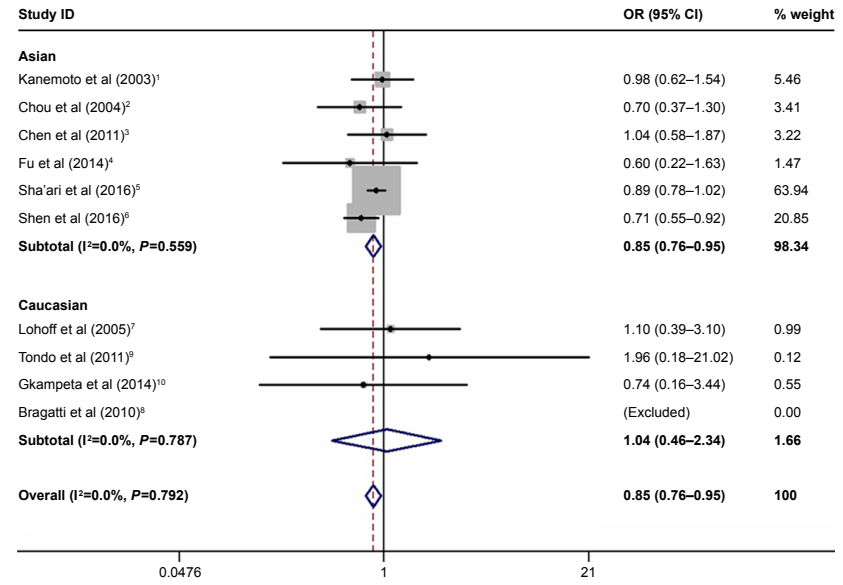

Figure SI OR and $95 \%$ Cls of the associations between BDNF rs6265 G>A polymorphism and epilepsy susceptibility (A for A vs G model; B for GA vs GG model; C for $A A$ vs $G G$ model; and $\mathbf{D}$ for $A A$ vs $G G+G A$ model).

A

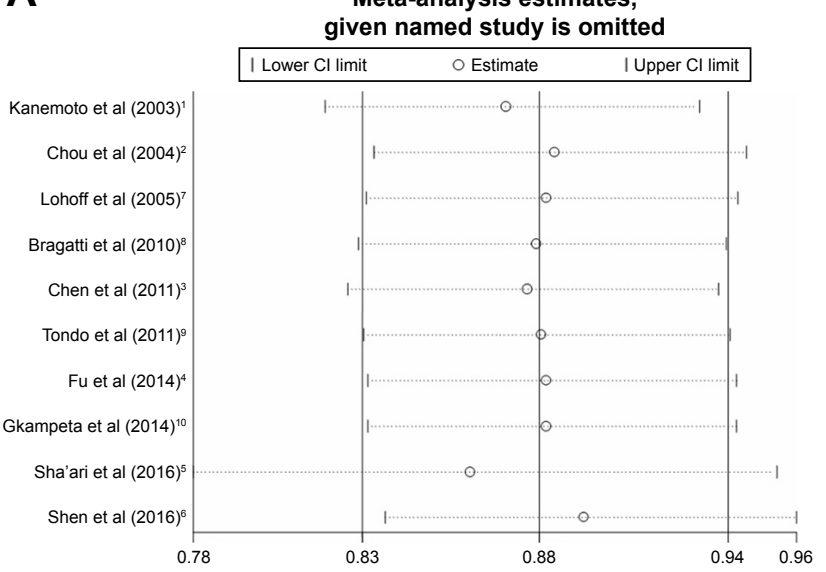

B

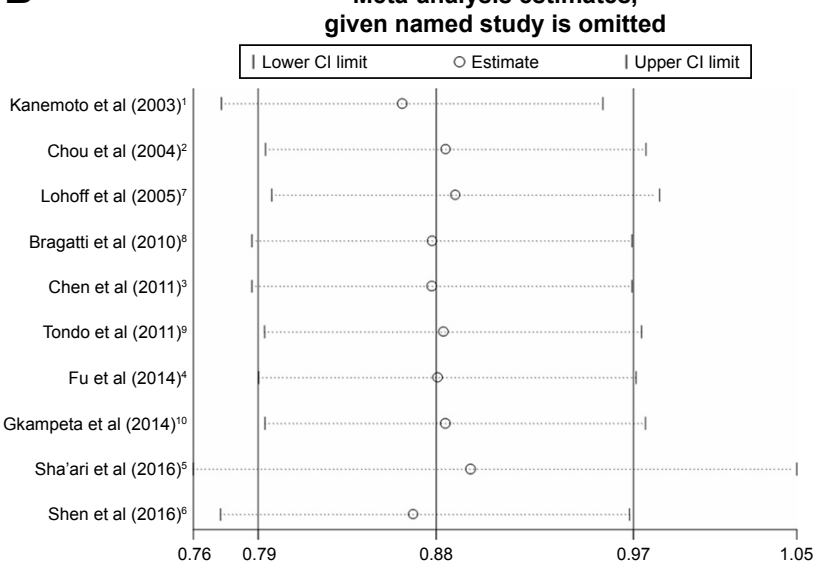

Figure S2 (Continued) 

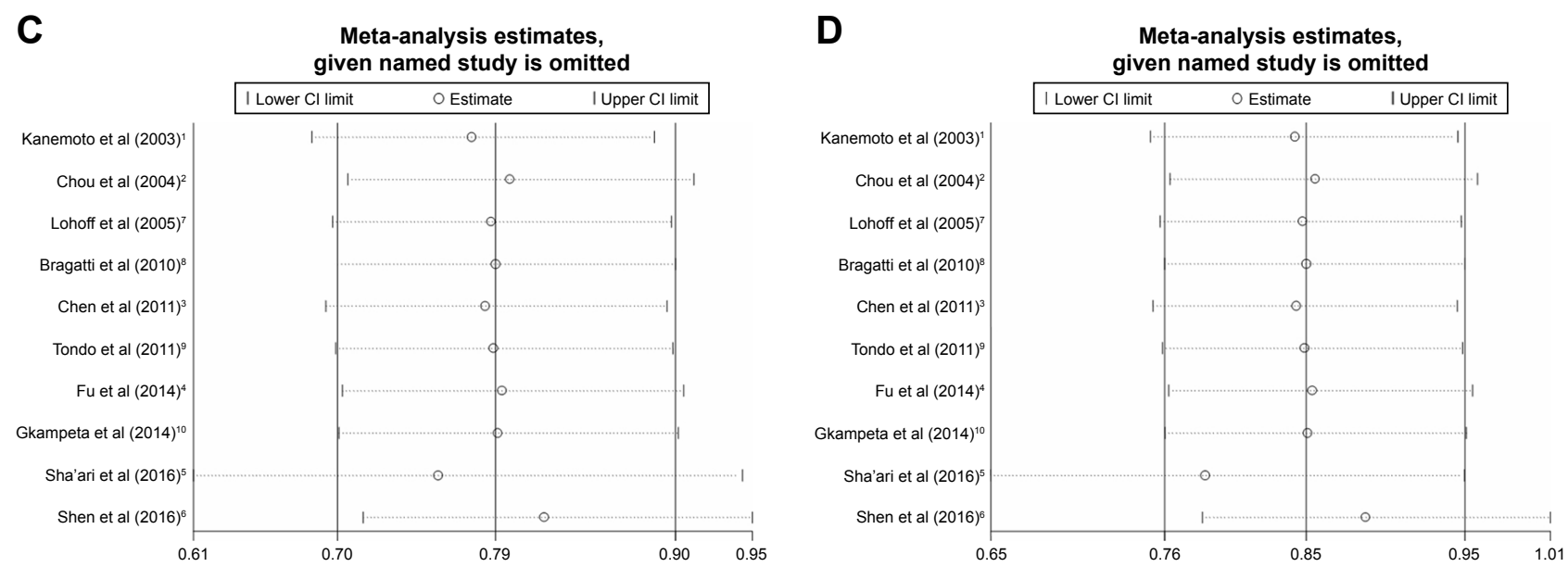

Figure S2 Sensitivity analysis through deleting each study to reflect the influence of the individual dataset to the pooled ORs in BDNF rs6265 G $>A$ polymorphism and epilepsy susceptibility (A for A vs G model; $\mathbf{B}$ for GA vs GG model; $\mathbf{C}$ for AA vs GG model; and $\mathbf{D}$ for AA vs GG+GA model).

A

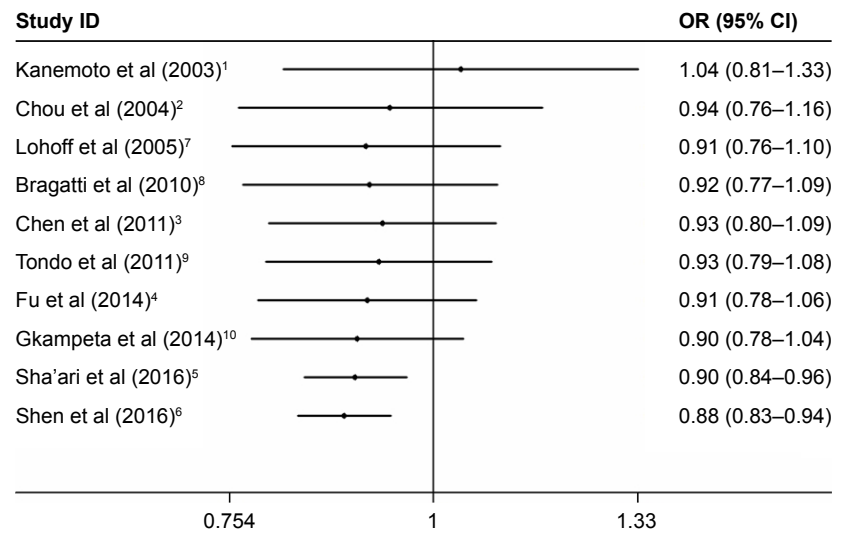

\section{C}

Study ID

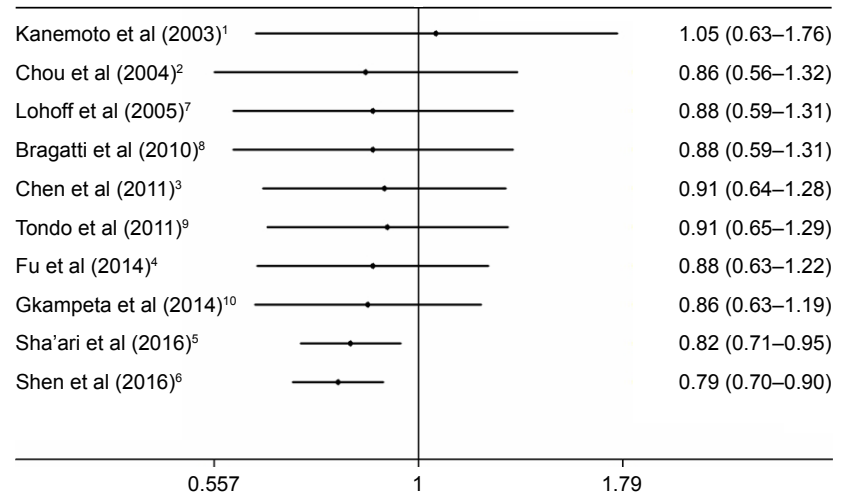

B Study ID OR $(95 \% \mathrm{CI})$

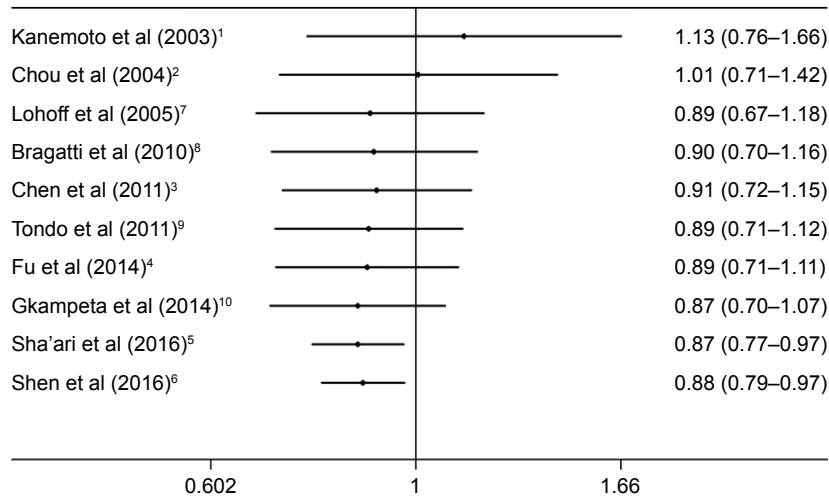

D

Study ID OR $(95 \% \mathrm{Cl})$

Kanemoto et al (2003) Chou et al (2004) Lohoff et al (2005) 7 Bragatti et al (2010) Chen et al (2011) Tondo et al $(2011)^{9}$ Fu et al $(2014)^{4}$ Gkampeta et al (2014) ${ }^{10}$ Sha'ari et al $(2016)^{5}$ Shen et al $(2016)^{6}$

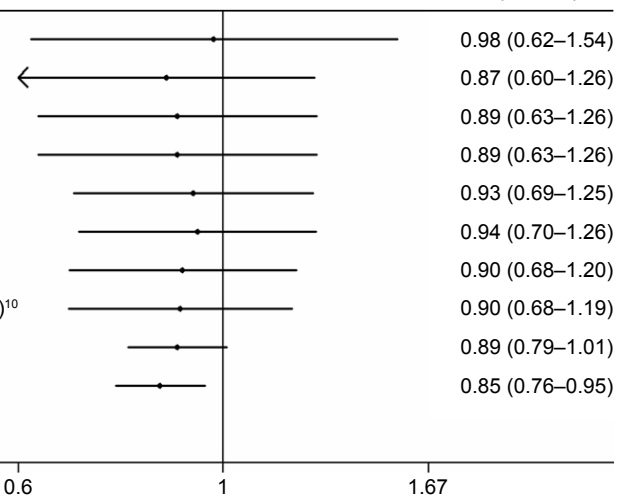

Figure S3 Cumulative meta-analyses according to publication year in BDNF rs6265 G>A polymorphism and epilepsy susceptibility (A for A vs G model; B for GA vs GG model; $\mathbf{C}$ for AA vs GG model; and $\mathbf{D}$ for AA vs GG+GA model). 


\section{A Begg's funnel plot with pseudo
$95 \%$ confidence limits}

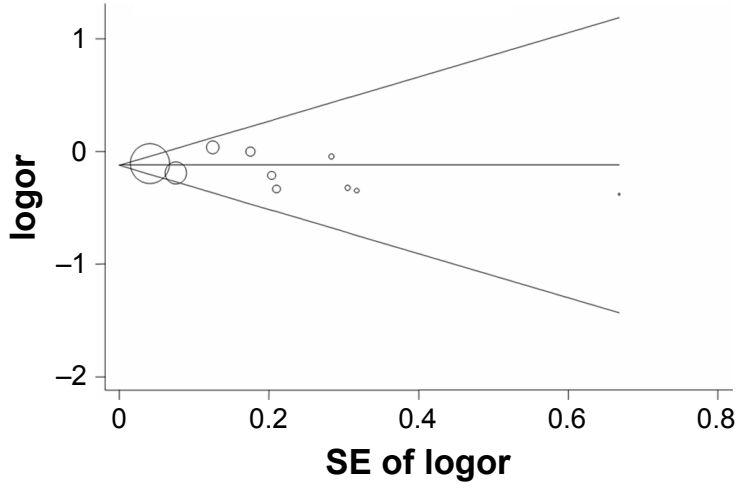

C Begg's funnel plot with pseudo $95 \%$ confidence limits

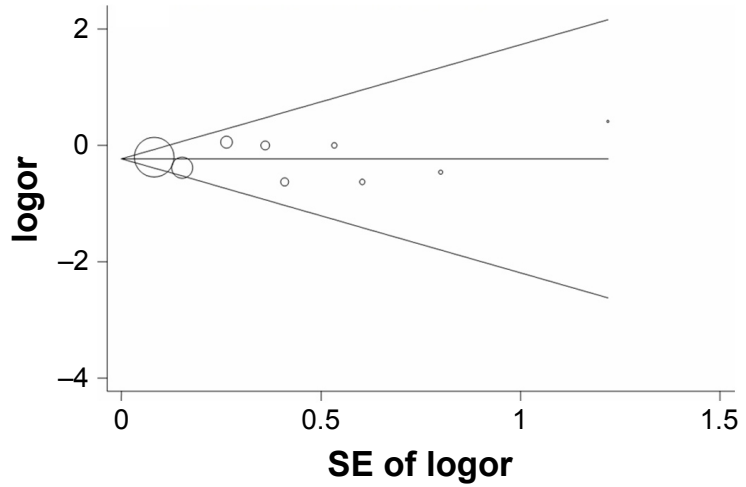

B

\section{Begg's funnel plot with pseudo $95 \%$ confidence limits}

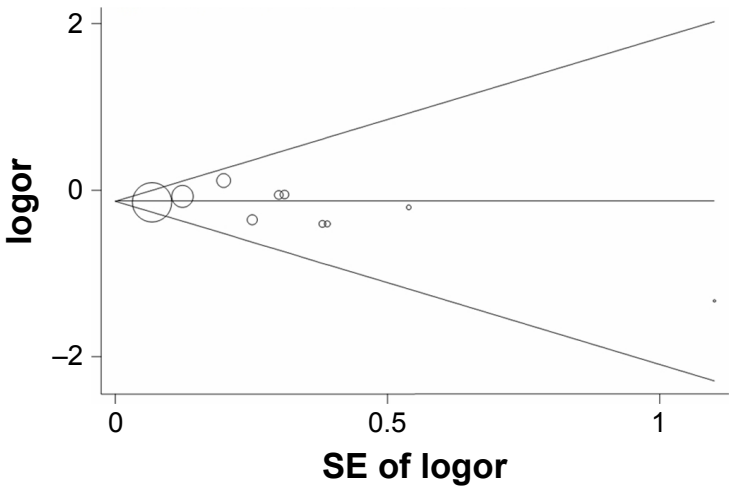

D Begg's funnel plot with pseudo $95 \%$ confidence limits

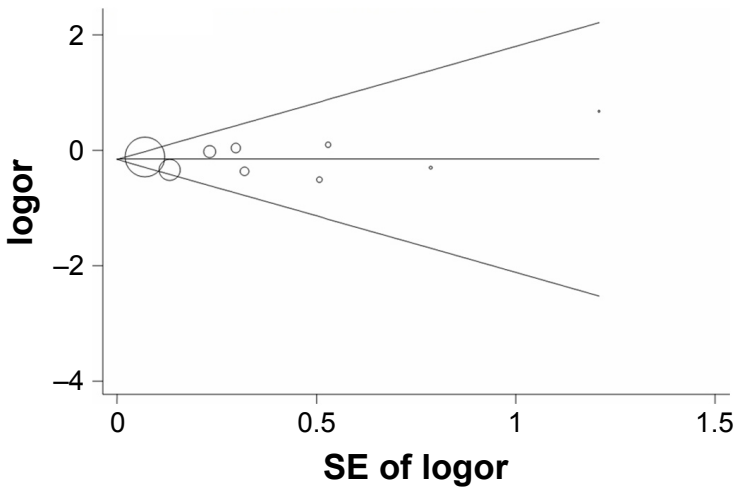

Figure S4 Funnel plot analysis to detect publication bias in BDNF rs6265 G>A polymorphism and epilepsy susceptibility (A for A vs G model; B for GA vs GG model; C for AA vs GG model; and D for AA vs GG+GA model).

\section{References}

1. Kanemoto K, Kawasaki J, Tarao Y, et al. Association of partial epilepsy with brain-derived neurotrophic factor (BDNF) gene polymorphisms. Epilepsy Res. 2003;53(3):255-258.

2. Chou IC, Tsai CH, Lee CC, Lin SS, Tsai FJ. Brain-derived neurotrophic factor (BDNF) Val66Met polymorphisms in febrile seizures. Epilepsy Res. 2004;60(1):27-29.

3. Chen Y, Wang J, Li F, Qin Y, Huang J. Association of brain-derived neurotrophic factor gene polymorphisms with the risk of pediatric epilepsy. Chin J Behav Med \& Brain Sci. 2011;20(10):907-909. Chinese.

4. Fu L, Luo C, Su B, et al. Study on the correlation between BDNF gene polymorphism and patients with temporal lobe epilepsy. Clin Med Eng. 2014;21(7):835-826. Chinese.

5. Sha'ari HM, Haerian BS, Baum L, et al. Association of BDNF polymorphisms with the risk of epilepsy: a multicenter study. Mol Neurobiol. 2016;53(5):2869-2877.
6. Shen N, Zhu X, Lin H, et al. Role of BDNF Val66Met functional polymorphism in temporal lobe epilepsy. Int J Neurosci. 2016;126(5): 436-441.

7. Lohoff FW, Ferraro TN, Dahl JP, et al. Lack of association between variations in the brain-derived neurotrophic factor (BDNF) gene and temporal lobe epilepsy. Epilepsy Res. 2005;66(1-3):59-62.

8. Bragatti JA, Schenkel LC, Torres CM, et al. No major clinical impact of Val66Met BDNF gene polymorphism on temporal lobe epilepsy. Epilepsy Res. 2010;88(2-3):108-111.

9. Tondo M, Poo P, Naudo M, et al. Predisposition to epilepsy in fragile $X$ syndrome: does the Val66Met polymorphism in the BDNF gene play a role? Epilepsy Behav. 2011;22(3):581-583.

10. Gkampeta A, Fidani L, Clarimon J, et al. Association of brain-derived neurotrophic factor (BDNF) and elongator protein complex 4 (ELP4) polymorphisms with benign epilepsy with centrotemporal spikes in a Greek population. Epilepsy Res. 2014;108(10): 1734-1739.

\section{Dovepress}

\section{Publish your work in this journal}

Neuropsychiatric Disease and Treatment is an international, peerreviewed journal of clinical therapeutics and pharmacology focusing on concise rapid reporting of clinical or pre-clinical studies on a range of neuropsychiatric and neurological disorders. This journal is indexed on PubMed Central, the 'PsycINFO' database and CAS,

and is the official journal of The International Neuropsychiatric Association (INA). The manuscript management system is completely online and includes a very quick and fair peer-review system, which is all easy to use. Visit http://www.dovepress.com/testimonials.php to read real quotes from published authors. 